\title{
Electrical alternans of TU wave in Romano-Ward syndrome
}

\author{
Kazumasa Hiejima and Toyomi Sano \\ From the Department of Medicine and Institute for Cardiovascular Diseases, Tokyo Medical and Dental \\ University, Tokyo, fapan
}

$A$ case is presented in which an exceptional electrical alternans of the $T U$ wave occurred in association with the Romano-Ward syndrome. This appears to be the first reported example of this association. Ventricular fibrillation was documented during the syncopal attacks. There was no evidence of abnormality of the serum electrolytes.

Electrical alternans of a single wave on the electrocardiogram is uncommon, and in particular TU or $\mathrm{U}$ wave alternans is an extremely rare phenomenon. The electrophysiological mechanism responsible for it has not been well defined. The following case with the Romano-Ward syndrome shows TU wave alternans without changes in the QRS complex.

\section{Case report}

A 67-year-old woman was admitted to hospital on 20 May 1971 after experiencing several syncopal episodes. The attacks first started when she was a schoolgirl. Since the age of 20 she had experienced syncopal attacks while taking a bath. For a few days before admission she had fever, increased frequency of micturition, and syncopal attacks, with convulsions at times.

On admission she was confused and had a temperature of $38^{\circ} \mathrm{C}$. The blood pressure was $150 / 90 \mathrm{mmHg}(20 / 12$ $\mathrm{kPa}$ ). Convulsions occurred suddenly, with facial cyanosis and incontinence. The attacks lasted for a few minutes. Physical examination in the conscious state was within normal limits except for spinal scoliosis. Chest radiographs and encephalograms were normal. Laboratory examinations showed a slightly disturbed liver function (AST, 68, ALT, 75, and LD 430 units) and renal function (BUN $45 \mathrm{mg} / \mathrm{dl}$ ), and mild anaemia (red blood cells $3.4 \times 10^{12} / 1$; white blood cells $3.5 \times 10^{\circ} / 1$; and a haemoglobin $12 \mathrm{~g} / \mathrm{dl}$. All serum electrolytes including $\mathrm{Na}, \mathrm{K}, \mathrm{Cl}, \mathrm{Ca}$, and phosphate were within normal limits. Urinalysis showed a trace of albumin, 1+ sugar, 14-17 red blood cells and many white blood cells per high-power field. Urine culture showed Pseudomonas aeruginosa and Gram-positive bacilli, from which a diagnosis of acute urinary tract infection was made.

An electrocardiogram taken during the attacks showed ventricular fibrillation (Fig. 1). On the second day in hospital the TU wave alternans was recorded (Fig. 2). There was no change in the QRS complex. The interpretation of this finding is discussed below.

Although the patient was free from any syncopal attacks during hospitalization except on the day of admission, phenobarbitone, ajmaline, and theophyllineethylenediamine were administered for the convulsive attacks. She was also treated for acute urinary tract infection with kanamycin and nalidixic acid. The laboratory data improved considerably and she was discharged on 23 June 1971, but subsequently seen at intervals thereafter.

Electrocardiagrams recorded at various times are shown in Fig. 3; there appear to be prolonged QT intervals in Fig. 3A and 3C, with no definable $U$ wave. In Fig. 3B leads I, II, III, and aVF appear to show QT prolongation, but leads V3, V5, and V6 show a prominent $U$ wave, suggesting that the delayed repolarization wave in leads I, II, and III is a combined TU wave.

The patient's family history was as follows. She was the eldest of eight sibs and only the second sister is alive besides the patient. The QT interval on her electrocardiogram was also prolonged, being $0.47 \mathrm{~s}$. Six other sibs and both parents died of diseases unrelated to syncopal attacks. The family of the mother's sister, whose spouse was a cousin of the patient's father, is worth noting. She had seven children. Three of them died suddenly at the ages of 2 to 3 ; one of them died suddenly on a public transport vehicle. Three others grew up and are living, and one of them is now in a provincial hospital (Fig. 4).

\section{Discussion}

Jervell and Lange-Nielsen (1957) first described a syndrome consisting of congenital deaf-mutism, prolongation of the QT interval, syncope, and 


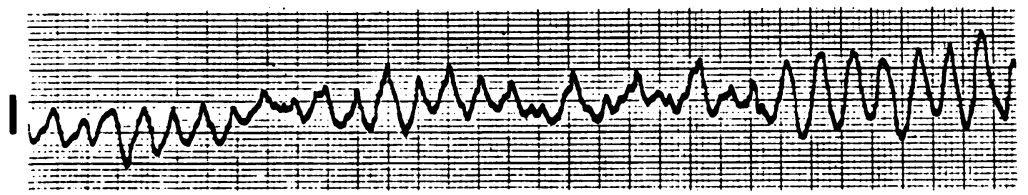

FIG. 1 Ventricular fibrillation during syncopal attacks.

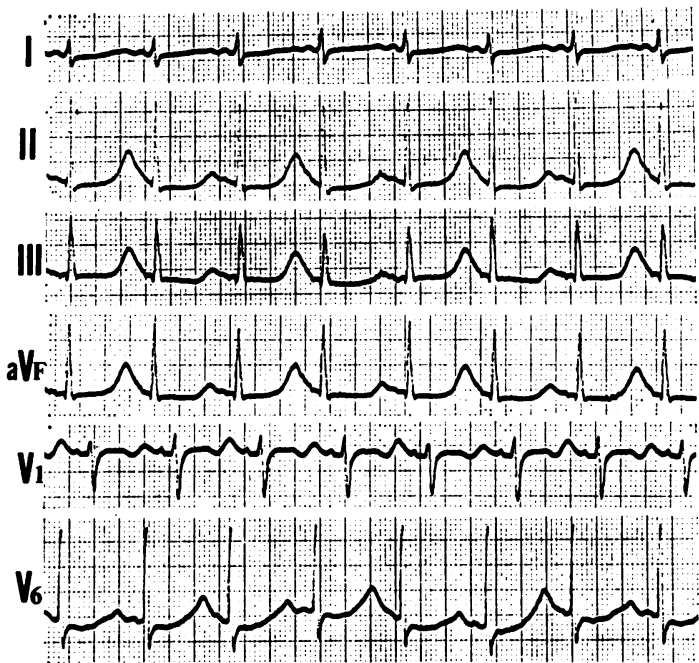

FIG. 2 An electrocardiogram obtained on the day after admission. $T U$ wave alternans is conspicuous.

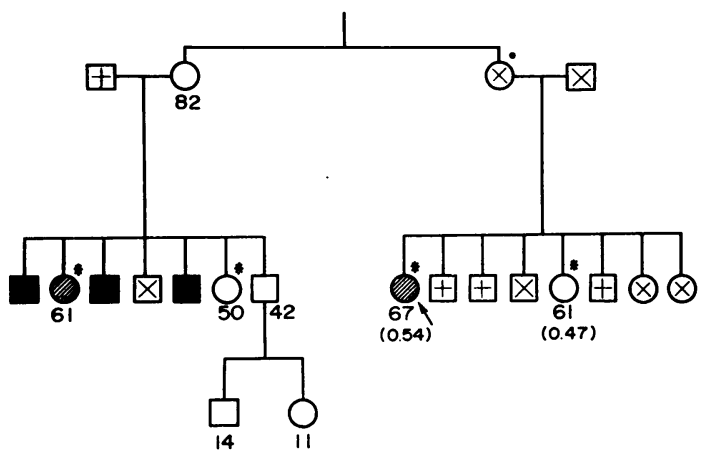

FIG. 4 Pedigree of the family of our case. Numbers denote age in years and figures in parentheses the QTc interval. The arrow indicates the propositus. Symbols are as follows:

* unmarried; - hypertensive; $⿴$ died of pulmonary tuberculosis; — died suddenly;

冈or $\otimes$ died of other causes; and $\bigcirc$ history of syncopal attacks.
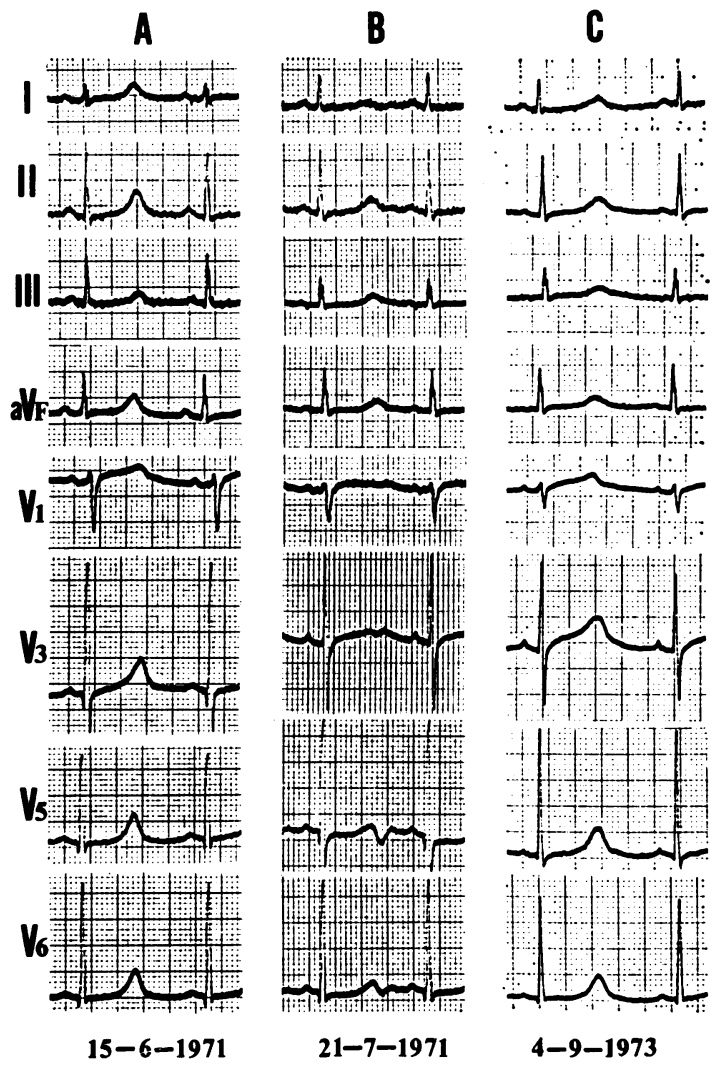

FIG. 3 Changes of $T$ or $T U$ wave. For details see text.

sudden death. Later, Romano, Gemme, and Pongiglione (1963) and then later Ward (1964) reported on a similar syndrome characterized by QT prolongation, syncope, and sudden death but unassociated with deaf-mutism. In both cases QT prolongation was caused neither by extracellular hypopotassaemia nor by hypocalcaemia. It is evident that there is more clinical significance in the latter syndrome than in the former in that the syncope or sudden death occurs in apparently otherwise healthy children or adults. As regards 
heritable QT prolongation without deaf-mutism, the so-called Romano-Ward syndrome, 20 families consisting of 85 affected members have been reported to date (Hiejima, 1975).

In the case observed by us there had been repeated attacks of syncope since childhood, prolongation of the QT interval not due to the abnormal extracellular electrolytes, and familial occurrence of syncope and sudden death. Accordingly, there seems to be little doubt that the present case represents an example of the Romano-Ward syndrome. In addition the patient showed a transient alternation of the TU or the $U$ wave. Alternating variation of the $T$ wave can be seen in Fig. 5 of Romano et al. (1963), where alternate beats show upright and inverted delayed $T$ waves.

The identification of the wave showing alternans as a U wave was based on Lepeschkin's criteria (1969): (1) The wave in question appears extremely late in diastole in leads II, III, and AVF. Lepeschkin published a nomogram showing the time relation between the apex of the $T$ and that of the $U$ at different $Q-Q$ intervals. Employing this, we considered the apex of the wave in question could be that of the $U$ wave. However, it is difficult to be certain that it is in order to apply the Lepeschkin nomogram to this patient in the absence of any method by which a pathologically delayed $T$ can be separately identified from the $U$. (2) When the electrogram of Fig. 3A was taken, a phonocardiogram was also recorded (not shown). In simultaneously recorded lead II the apex of the wave in question appeared $0.01 \mathrm{~s}$ before the beginning of the second heart sound. Lepeschkin stated that, if the apex of a questionable wave appears before the second heart sound, it is part of the $T$ wave, whereas if it appears later than $0.03 \mathrm{~s}$ after the beginning of the second heart sound it is almost certainly formed by the apex of a $U$ wave. Consequently the wave in question in Fig. $3 \mathrm{~A}$ is a $\mathrm{T}$ wave. In contrast a wave with two positive peaks is seen in leads V3 and V5 in Fig. 3B. The second peak of these waves is unlikely to be a $T$ wave but most likely to be a $U$ wave, since they appear later than the peak of the wave now considered to be a $T$ wave in Fig. $3 A$ in spite of the shorter $Q-Q$ interval. Particularly in lead V5 the interval between these two apices is $0.16 \mathrm{~s}$. According to Lepeschkin the apices of diphasic $T$ wave are usually less than $0.15 \mathrm{~s}$ apart, whereas the interval between the $T$ and $U$ apices is usually greater than $0.15 \mathrm{~s}$. Therefore, the second peak in lead V5 is consistent with the $U$ wave. At the time of the recording of the tracing on 21 July 1971 the patient clearly had a $U$ wave, which was not easily identified separately in other tracings. On this account it is suggested that the peak of the wave showing alternans in Fig. 2 may also be the U wave, and the repolarization wave in V1 suggests that an inverted $T$ component may precede $U$ waves of alternating high and low amplitude. The wave showing alternans may therefore be either a $U$ wave or a complex TU.

The occurrence of the TU or $U$ wave alternans is an exceptionally rare phenomenon. To our knowledge there is only one such report, by Bashour, Rios, and Gorman (1973). Their case resembles ours closely and shows a huge $U$ wave alternans. They did not mention, however, why they regarded the alternated wave as the $U$ wave. Furthermore, the apex of the wave showing alternans in their case (their Fig. 2) appeared earlier than in our case. Though the interval from the beginning of the QRS complex to this apex was almost equal $(0.48 \mathrm{~s})$, there was a difference in the $\mathrm{Q}-\mathrm{Q}$ interval $(0.76 \mathrm{~s}$ in their case against $0.68 \mathrm{~s}$ in ours). The superimposition of $T$ wave alternans cannot be excluded either. Though ventricular fibrillation was also observed in their case, the case is not consistent with the Romano-Ward syndrome, because there were moderate hypomagnesaemia, mild hypocalcaemia, and absence of familial occurrence. Fraser, Froggatt, and James (1964) described a change of the repolarization wave which occurred after the patient became extremely apprehensive. The wave in Fig. 11B and $C$ of their paper might be similar to ours because of its late appearance, though they seemed to regard it as a $T$ wave. However, they did not mention it as an electrical alternans. The rhythm and shape of the waves are not exactly regular. The strip is too short to determine whether it is a $U$ wave alternans or not. Accordingly, our paper seems to be the first report of the TU wave alternans in the Romano-Ward syndrome.

Scherf and Bornemann (1971) described a larger $U$ wave in the first beat after a pause as a constantly recurring pattern in various arrhythmias. Mullican and Fisch (1964) described a case showing postextrasystolic alternans of the $U$ wave. Ten patients with left ventricular failure and postextrasystolic U wave alternans were reported by Eyer (1974). Kimura and Yoshida (1963), Ricketts, Denison, and Haywood (1969), and Dolara and Pozzi (1971) each reported on a case of the $T$ wave alternans. Whether these are due to a similar mechanism or not cannot be determined, since it is not yet clear whether the $U$ wave is a reflection of the Purkinje system repolarization, of afterpotential, or of any other events.

Experimental studies by Kleinfeld, Stein, and Kossmann (1963) suggested that alternation in the rate and extent of calcium and potassium transport across the myocardial cell membrane was responsible for $T$ wave alternans. The problem of 
electrical alternans of the $T$ wave has been further discussed by Schwartz and Mallini (1975), who ascribe the changes to asymmetrical sympathetic stimulation of the right and left sides of the heart, a mechanism which has been invoked by Yanowitz, Preston, and Abildskov (1966) to account for the basic QT prolongation in the syndrome. Mullican and Fisch (1964) ascribed their finding on the postextrasystolic alternans of the $U$ wave to hypopotassaemia. Bashour et al. (1973) attributed the U wave abnormality of their case to hypomagnesaemia with possible additional influence from concomitant hypocalcaemia. Ward (1966) examined the serum electrolytes before and after the exercise-induced attacks of syncope, and found that no gross change occurred in the extracellular electrolytes. Furthermore Johansson and Jorming (1972) gave their patient potassium chloride and magnesium sulphate intravenously and calcium acetate orally without effect. In our case all those electrolytes examined were within normal limits. The magnesium content of the blood was not examined, unfortunately.

Fraser et al. (1964) supposed that the prolongation of the QT interval in the Jervell-Lange-Nielsen syndrome was induced by a diffuse cardiac metabolic error suggested by lack of characteristic clear zone and bulge of the Purkinje fibres at necropsy. The mechanism of the prolongation of the QT interval in the Romano-Ward syndrome has not been fully elucidated yet.

Ventricular irritability has been emphasized in the Romano-Ward syndrome and ascribed to the prolongation of the QT interval. Han and Moe (1964) stated that temporal dispersal of repolarization may lead to instability during repolarization, or alternation may lead to a circus movement that may provoke ventricular fibrillation. There may be more chance of the premature beat hitting the vulnerable period of the preceding beat. Wellens, Vermeulen, and Durrer (1972) did not find greater differences in functional refractory period at different sites in right and left ventricle at different driving rates. Their patient showed a considerable $U$ wave, which made it impossible to determine the true length of the QT interval. The QT was considered to be normal at rest, but after auditory stimulation it became prolonged, and the case probably belongs to the Romano-Ward category, which makes the observation of the absence of a variation in refractory periods in different areas of the heart muscle relevant to this discussion.

\section{References}

Bashour, T., Rios, J. C., and Gorman, P. A. (1973). U wave alternans and increased ventricular irritability. Chest, 64, 377.

Dolara, A., and Pozzi, L. (1971). Electrical alternation of T wave without change in QRS complex. British Heart fournal, 33, 161.

Eyer, K. M. (1974). U wave alternans: an electrocardiographic sign of left ventricular failure. American Heart fournal, 87, 41.

Fraser, G. R., Froggatt, P., and James, T. N. (1964). Congenital deafness associated with electrocardiographic abnormalities, fainting attacks and sudden death. Quarterly fournal of Medicine, 33, 361.

Han, J., and Moe, G. K. (1964). Nonuniform recovery of excitability in ventricular muscle. Circulation Research, $14,44$.

Hiejima, K. (1975). Romano-Ward syndrome. Shinzo (Heart), 7,146 (in Japanese).

Jervell, A., and Lange-Nielsen, F. (1957). Congenital deafmutism, functional heart disease, with prolongation of the Q-T interval, and sudden death. American Heart fournal, $54,59$.

Johansson, B. W., and Jorming, B. (1972). Hereditary prolongation of QT interval. British Heart fournal, 34, 744.

Kimura, E., and Yoshida, K. (1963). A case showing electrical alternans of the $T$ wave without change in the $Q R S$ complex. American Heart fournal, 65, 391.

Kleinfeld, M., Stein, E., and Kossmann, C. E. (1963). Electrical alternans with emphasis on recent observations made by means of single-cell electrical recording. American Heart fournal, 65, 495.

Lepeschkin, E. (1969). The U wave of the electrocardiogram. Modern Concepts of Cardiovascular Disease, 38, 39.

Mullican, W. S., Jr., and Fisch, C. (1964). Postextrasystolic alternans of the $U$ wave due to hypokalemia. American Heart fournal, 68, 383.

Ricketts, H. H., Denison, E. K., and Haywood, L. J. (1969). Unusual T-wave abnormality. Fournal of the American Medical Association, 207, 365.

Romano, C., Gemme, G., and Pongiglione. R. (1963). Aritmie cardiache rare dell'eta' pediatrica. Clinica Pediatrica, 45, 656.

Scherf, D., and Bornemann, C. (1971). The U waves in cardiac arrhythmias. Geriatrics, 26, February, 140.

Schwartz, P. J., and Mallini, A. (1975). Electrical alternation of T wave. American Heart fournal, 89, 45.

Ward, O. C. (1964). A new familial cardiac syndrome in children. Fournal of the Irish Medical Association, 54, 103.

Ward, O. C. (1966). The electrocardiographic abnormality in familial cardiac arrhythmia. Irish fournal of Medical Science, 6th Series, No. 491, 553.

Wellens, H. J. J., Vermeulen, A., and Durrer, D. (1972). Ventricular fibrillation occurring on arousal from sleep by auditory stimuli. Circulation, 46, 661 .

Yanowitz, F., Preston, J. B., and Abildskov, J. A. (1966). Functional distribution of the right and left stellate innervation to the ventricles. Circulation Research, 18, 416.

Requests for reprints to Dr. K. Hiejima, Department of Medicine, Tokyo Medical and Dental University, No. 5-45, 1-chome, Yushima, Bunkyo-ku, Tokyo, Japan. 